Abstracta Iranica

Revue bibliographique pour le domaine irano-aryen

Volume 37-38-39 | 2018

Comptes rendus des publications de 2014-2016

\title{
Jari Kaukua. Self-Awareness in Islamic Philosophy: Avicenna and Beyond
}

\section{Amélie Neuve-Eglise}

\section{OpenEdition}

1 Journals

\section{Édition électronique}

URL : http://journals.openedition.org/abstractairanica/43967

DOI : 10.4000/abstractairanica.43967

ISBN : 1961-960X

ISSN : 1961-960X

Éditeur :

CNRS (UMR 7528 Mondes iraniens et indiens), Éditions de l'IFRI

Référence électronique

Amélie Neuve-Eglise, " Jari Kaukua. Self-Awareness in Islamic Philosophy: Avicenna and Beyond", Abstracta Iranica [En ligne], Volume 37-38-39 | 2018, document 1, mis en ligne le 30 décembre 2018, consulté le 10 décembre 2020. URL : http://journals.openedition.org/abstractairanica/43967 ; DOI https://doi.org/10.4000/abstractairanica.43967

Ce document a été généré automatiquement le 10 décembre 2020.

Tous droits réservés 


\title{
Jari Kaukua. Self-Awareness in Islamic Philosophy: Avicenna and Beyond
}

\author{
Amélie Neuve-Eglise
}

\section{RÉFÉRENCE}

Jari Kaukua. Self-Awareness in Islamic Philosophy: Avicenna and Beyond. Cambridge :

Cambridge University Press, 2015, 257 p.

1 L'ouvrage aborde la question de la conscience de soi (šu'ūr bi-d̄ât) et de la nature du soi dans la philosophie islamique, en partant de l'idée que ces sujets en constituent une thématique à part entière à partir du XIe siècle. Le rôle du phénomène de la conscience de soi dans la psychologie d'auteurs comme Avicenne, Sohravardī et Mullā Șadrāa ainsi que les questionnements épistémologiques et métaphysiques qu'il implique sont analysés sur la base d'extraits variés d'œuvres originales de ces auteurs.

2 Une partie importante de l'ouvrage est consacrée à la façon de concevoir le soi et la conscience de soi dans la pensée avicennienne, en partant d'une analyse critique détaillée notamment de l'argument' de l'Homme volant et de son rôle dans l'affirmation de l'existence de l'âme comme substance immatérielle. L'A. insiste ainsi particulièrement sur les liens entre la question de la conscience de soi chez Avicenne et sa psychologie dualiste fondant l'individualité dans la relation d'une substance immatérielle à la matière, en s'appuyant principalement sur le Traité de l'Âme du Shifā', mais aussi en élargissant le corpus d'analyse aux Išārāt, Mubāḥatāât, et Ta līqāt. D'autres arguments avancés par Avicenne, dont celui partant de l'unité de l'expérience, sont étudiés en vue d'étayer l'idée que la conscience de soi est un concept distinct et une thématique à part entière de sa pensée.

3 L'A. aborde aussi la façon dont sa réflexion au sujet des caractéristiques de la conscience humaine de soi permet à Avicenne d'apporter un éclairage sur des questions d'ordre métaphysique et théologique, dont celle de la connaissance que Dieu a de Luimême et de Sa création. 
4 La pensée avicennienne est ensuite confrontée de façon succincte aux critiques d'Abū al-Barakāt al-Bağdādī et de FaH̆r al-Dīn al-Rāzī, avant que ne soient abordées sa réception et réinterprétation par ses successeurs - essentiellement Sohravardī et Mullā Șadrā.

5 L'A. expose ainsi de façon précise la façon dont la description avicennienne de la conscience de soi est reprise et transformée pour devenir une pièce maîtresse non plus seulement de la psychologie, mais de la métaphysique sohravardienne, notamment dans la définition de ses concepts de connaissance comme présence (hudūur), et d'être comme lumière (nūr) ou apparence (zuhūr). En s'appuyant sur de nombreux extraits de son œuvre, il met avant la déconnexion opérée entre conscience de soi et substantialité, qui sera approfondie dans la philosophie sadrienne.

6 Deux chapitres sont consacrés à la façon dont l'argumentaire avicennien a été réinterprété par Mullā Șadrā, la conscience de soi devenant une forme d'existence ou un mode d'existence mentale (wujūd dihnī) dans le cadre de son système métaphysique fondé sur l'authenticité de l'être (ișālat al-wujūd). La conscience de soi sort ici du monolithisme statique de la substance, pour devenir une réalité modulée dont les attributs connaissent une perpétuelle évolution en fonction de son interaction avec le monde extérieur.

7 Ce travail, fruit de la thèse de doctorat de l'A. et de ses recherches ultérieures consacrées à la connaissance dans la philosophie islamique post-avicennienne, a l'intérêt de montrer l'existence d'une réflexion sur la question du soi individuel dans un contexte pré-moderne. L'analyse se distingue par un grand sens de la nuance (notamment des difficultés liées à la compréhension du mot dāt pouvant à la fois désigner le soi ou l'essence), des analyses philologiques précises, et une constante attention à ne pas commettre d'anachronisme en plaquant des questionnements plus modernes du soi sur cette tradition de pensée.

8 Une mise en perspective avec la tradition mystique, et notamment la façon dont cette question a été abordée par Ibn 'Arabī, aurait pu conférer davantage de profondeur à l'analyse. On regrettera aussi l'absence de présentation des réflexions plus contemporaines sur la thématique de la conscience de soi, notamment celle de 'Allāme Ṭabāṭabā'ì.

9 L'ouvrage apporte néanmoins une contribution notable et d'une grande précision à la fois historique et philosophique à la question, en la situant dans des enjeux philosophiques plus larges propres à chaque penseur. Notons que cette question a récemment été abordée par d'autres auteurs, dont Ahmed Alwishah (2016), qui viennent enrichir - et parfois questionner - l'argumentaire de Kaukua.

\section{AUTEURS}

\section{AMÉLIE NEUVE-EGLISE}

Paris 